\title{
LITERATURA E METAFÍSICA NA FILOSOFIA DE SIMONE DE BEAUVOIR
}

\author{
LITERATURE AND METAPHYSICS IN THE PHILOSOPHY OF SIMONE DE BEAUVOIR
}

Pedro Rhavel Teixeira*

\section{RESUMO:}

Este trabalho tem por objetivo apresentar o ensaio Literatura e metafísica de Simone de Beauvoir. Em seguida, se estabelecerá a relação entre filosofia e literatura na obra da autora, mostrando como ambas as instâncias se imbricam e não podem ser compreendidas como saberes totalmente distintos, separados. Ao fim, mostrar-se-á através de trechos de seu romance $A$ convidada a forma como a filósofa francesa concilia filosofia e literatura.

PALAVRAS-CHAVE: Literatura. Filosofia. Simone de Beauvoir. Filosofia Contemporânea. Teoria da Literatura.

\section{ABSTRACT:}

This paper aims to introduce Simone de Beauvoir's essay Literature and metaphysics. Then, it will establish the relationship between philosophy and literature in author's books, revealing how both philosophy and literature, instances crossing each other and cannot be understood as distinct knowledge; apart. In the end, the path through which the French philosopher conciliates literature and philosophy will be shown in excerpts from her book She came to stay.

KEY WORDS: Literature. Philosophy. Simone de Beauvoir. Contemporary Philosophy. Theory of Literature.

Grande parte da obra de Beauvoir é literária. A autora escreveu romances, contos e autobiografias. Mas por que Simone de Beauvoir se lança na experiência literária em detrimento da filosofia? Para responder essa questão, a autora escreve um pequeno ensaio, intitulado Literatura e metafísica. Cabe-nos analisá-lo, para chegar ao menos a um palpite, um direcionamento acerca de suas motivações.

Da mesma forma que em Pirro e Cinéias, Beauvoir parte de uma parábola para apresentar sua questão. O tema do ensaio é o porquê do agir. Simone de Beauvoir vai passo a passo desmantelando, desmanchando, mostrando em análise todas as predeterminações que estão em uma espécie de invólucro; todas as essências possíveis das ações. Chega a afirmar que nada possui sentido próprio e que, como todas as coisas, a ação só possui sentido posterior, ou melhor, a ação passa a fazer sentido em sua própria execução. No caso particular da pensadora francesa, o seu significado é alcançado na escrita; em uma escrita íntima, que

\footnotetext{
* Bacharel em filosofia (UFRJ), Mestre em filosofia (PPGF-IFCS), Doutorando em filosofia (PPGF-IFCS), Bolsista da CAPES. E-mail: prhavel@gmail.com.
} 
transforma as emoções e experiências vividas em literatura, em romance. É nesse gênero literário que ela se realiza e propõe grande parte da sua própria filosofia (SIMONS, 1989, p. 13). A separação entre literatura e filosofia não é clara nos romances de Beauvoir. Sua obra, avaliada em sua totalidade, é um amálgama composto por esses dois elementos. Se é verdade que filosofia e literatura são distintas uma da outra, os romances de Beauvoir nos servem como um claro exemplo de que é possível juntá-las sem perdas.

A partir da ideia de que filosofia e literatura seriam coisas distintas, a escritora francesa escreve um pequeno ensaio chamado "Literatura e metafísica". Sua primeira indagação é sobre o sentido de se aventurar na literatura após ter lido os grandes nomes da história da filosofia. Parecia pueril à autora de $O$ segundo sexo retornar à literatura após ter estudado filosofia e apreendido os grandes sistemas universais. Em uma evidente ironia, Beauvoir expõe um tipo específico de romance, ou melhor, um conceito criado por ela. $\mathrm{O}$ romance metafísico é o lugar próprio de expor filosofia através da literatura. É apreender o mundo como um objeto e em seguida transformá-lo em texto, em uma trama na qual a ambiguidade é escancarada. Este seria o melhor espaço, ou o espaço beauvoiriano, de expor e compor filosofia.

Segundo Eliana Calado, autora de Autobiografias de Simone de Beauvoir: sujeito, identidade, alteridade, uma característica retórica da obra literária de Beauvoir é o uso do sinal de dois pontos. O sinal, cujo significado é idêntico ao de igual na matemática, foi uma das maiores estratégias retóricas utilizadas por Beauvoir (CALADO, 2011, p. 12). Era a forma de a autora introduzir suas próprias conclusões. Levava consigo o leitor pela mão. Sua escrita não tinha mistérios, o caminho a ser trilhado era posto, e o leitor que a acompanhasse rumo à narrativa. Não se trata de um texto concebido com retórica forçosa ou mesmo linguajar arcaico, e sim de narrativa que incide no ponto; a estrada que o próprio leitor terá, quase que por obrigação de percorrer. Com efeito, o pensamento então era exposto através de descrições, objetos, cenas, pequenos fluxos de consciência, em que o eu de cada personagem só aparece através do olhar do outro. A proposta de Calado é demonstrar que o artifício retórico do uso de dois pontos é uma forma de demonstrar a intenção de Beauvoir, de conduzir o leitor em uma determinada jornada que tem de ser acompanhada segundo as regras da autora. Não há escape, desvios; ou se segue a proposta de Beauvoir ou se abandona seu romance.

O eu possui uma imagem própria, mas esta só nos é conhecida pelos olhos dos outros. A alteridade é reafirmada como a grande questão filosófica de Beauvoir e dentro de sua obra 
não se trata de estabelecer qualquer juízo a respeito. Não é na busca insaciável de uma alteridade positiva que a escritora estava interessada, e sim na concretude da experiência do outro (SIMONS, 1979, p. 345), em como a consciência se realiza no aniquilamento de outra consciência, desconsiderando-a como potência, ou mesmo na reciprocidade possível entre dois sujeitos. Tudo isso deveria estar em jogo; deveria ser exposto até a exaustão, para daí, no auge do pensamento como atividade espiritual reflexiva, extrair-se um significado; um sentido.

O leitor acaba por ser o único sujeito em $A$ convidada. Sua consciência se revela na medida em que apreende as personagens somente como outros. Ele, o leitor, sujeito e consciência absoluta, não é, contudo, um demiurgo. É evidente que os destinos já estão dados e só lhe resta acompanhar os desfechos. Assim, nessa pequena experiência de ser o outro, ele pode experimentar brevemente a experiência do outro. Justo por poder transitar entre os dois estágios é que se pode considerá-lo uma espécie de transcendente, se der as mãos a Beauvoir e seguir através de sua narrativa.

De volta à questão de Literatura e metafísica, é preciso apontar que o sentido dado ao termo metafísica é outro e não o usual do início deste texto. É o corpo que é metafísico para Beauvoir, na medida em que transcende, exerce algo para fora do comum, do imanente. A metafísica aqui não é externa ao mundo, ela é no próprio mundo uma forma de conceber as coisas, contrária à noção transcendental que a palavra carrega. Após a leitura de Fenomenologia da percepção, de Merleau-Ponty, Beauvoir $\left(1970^{\mathrm{a}}\right.$, p. 102) se atém ao corpo como lugar de realização, de transcendência. É nele que se habita, se compõe o mundo e que se age sobre ele. É o corpo o seu espaço, lugar de interesse. A concretude da experiência da alteridade se dá então no corpo e é também nele que se transcende a categoria de sujeito.

Em suma: não se faz metafísica, se é metafísico. Esse estado é uma atitude de encontro com o mundo, de encontro com a facticidade, e o que ela apresenta e representa na vida de cada existente. É somente com o corpo que se atinge a transcendência, que não é um estado imutável, nem mesmo um patamar de uma sequência teleológica. É, mais uma vez, um estado, uma condição diante da realidade. É uma forma de lidar com as coisas e com os outros no mundo.

A partir do breve esclarecimento sobre a prerrogativa do termo no texto beauvoiriano, devemos nos ater ao que a autora apresenta então como romance metafísico. O texto começa com uma indagação: onde é que se situa a verdade? Na superfície da terra ou sobre a eternidade? (BEAUVOIR, 1965, p. 79). O questionamento parece ter acompanhado toda a 
trajetória de vida de Beauvoir, já que nas entrevistas citadas ela propõe a recusa do título de filósofa em detrimento da alcunha de escritora (SIMONS, 1989, p. 13). A resposta, diz Beauvoir, situa-se no próprio mundo. É somente dele e a partir dele, em seu seio, que se pode situar a verdade e a própria noção de mundo. Simone elabora a resposta como uma perturbação que aflige todos os espíritos sensíveis, tanto à ficção quanto à filosofia.

Se a realidade é uma, ela tem e pode ser expressa na filosofia e na literatura por aqueles que estipulam uma cisão verdadeira entre as duas coisas, Contudo, há os espíritos que tentam abordar suas questões utilizando ambas as formas possíveis. Beauvoir é um desses espíritos que seguem já uma antiga tradição iniciada por Platão em seus diálogos. A forma de diálogo, entretanto, sugere uma relação intrínseca com o pensamento; com a conversa silenciosa que cada um, no seu íntimo, trava por escolha consigo mesmo. Já o romance, a poesia, o teatro e qualquer outra forma de literatura possível trabalham, sobretudo, com a faculdade da imaginação. Sendo então coisas distintas, uma vez que exercem influência sobre atividades e faculdades distintas, a saber, pensamento e imaginação, as categorias não se sobrepõem ou se hierarquizam, e sim coexistem.

Beauvoir reconhece que mesmo as obras que procuram recusar todo o sentido ainda dizem alguma coisa, mesmo que seja na manifestação da recusa. A autora ainda trabalha com dois fenômenos, que chama de romance metafísico e teatro de ideias, e nos adverte sobre as críticas que tais gêneros sofrem, pois para que traduzir em conceitos abstratos algo que pode ser expressado na economia da linguagem? Qual seria então a justificativa da existência do romance metafísico e do teatro de ideias? O que lhes é peculiar, diante do tratado filosófico e do romance? Aliás, como classificar uma obra dentro dessas duas percepções?

A resposta se daria pelo fato de a literatura se justificar quando ela é um modo de comunicação irredutível (BEAUVOIR, 1965, p 80). O filósofo e o ensaísta comunicam ao leitor a reconstrução de sua própria experiência intelectual, tal como se apresenta antes de qualquer elucidação. Por outro lado, o romancista, o poeta e o dramaturgo partem para reconstruir uma ideia no plano imaginário. Em seguida, trazem-na para o concreto na forma de obra. Segundo Beauvoir, no mundo real o sentido de um objeto não é apreendido como conceito pelo entendimento puro. É em um jogo de relações com o mundo que o objeto se revela; daí se deriva toda emoção, sentimento e ação. Diz ainda a autora francesa que esta é a tarefa legada àqueles que se aventuram na literatura: desvelar o sentido dos objetos do mundo, utilizando-se da imaginação, para dar conta de sua complexidade, escapando de qualquer percepção subjetiva. 
Mesmo a escrita mais intimista e particular há de revelar algum sentido comum, de certa maneira universal, em seu conteúdo. É dessa experiência contrária ao tratado filosófico, na medida em que parte do particular para o universal e não do seu oposto, fenômeno frequente nos tratados de filosofia, que Beauvoir está atrás. A distinção entre o teórico e o escritor se dá pelo fato de o primeiro querer constranger o leitor às ideias, e o segundo à coisa, ao objeto. O que distingue a boa literatura da má, para a escritora, é a capacidade de efetuar experiências tão complexas e inquietantes como as experiências vividas. Os movimentos postos em um texto comovem e entrelaçam o ser de modo a ser ele protagonista da própria ficção espelhada à sua frente.

O leitor acaba condenado a efetuar juízos que não lhe foram ditados por outrem. É sua própria atividade espiritual diante da obra que irá ditar o veredicto. É ele, o leitor, o ser inquirido pelo interrogatório. Em um momento terá que tomar partido, e esta elaboração é, para Beauvoir, mais enriquecedora do que qualquer doutrinação oriunda de uma leitura rígida sobre conceitos abstratos (BEAUVOIR, 1965, p. 81). Os conceitos na obra literária não são emitidos, elucidados. São forjados e vivenciados pelas personagens, pelo eu lírico ou sobre qualquer objeto narrado que esteja em questão.

É na recusa de uma clareza filosófica, uma ideia clara e distinta normativa, como propunha Descartes em suas Meditações, que o trabalho do literato se diferencia do filósofo. A questão e a ideia podem ser obscuras, cabendo ao leitor o papel de clareá-las. E é justamente essa busca, essa experiência que dá o valor, o sentido à obra literária de que o tratado filosófico carece. A literatura seria então contrária à filosofia. Obscura, subjetiva e indistinta.

O verdadeiro romance, diz Beauvoir, não se deixa reduzir a quaisquer fórmulas e nem mesmo as relata. $\mathrm{O}$ romance não pode se reduzir a um emaranhado de frases assertivas, ou meras descrições de cenas e ações. Ainda que a sua experiência perpasse a linguagem, seja feito de palavras, ele existe como os objetos do mundo, que ultrapassam qualquer coisa que possa ser dita. $\mathrm{O}$ autor, apesar de ter um desígnio específico, deve estar escondido, à espreita, para que a experiência romanesca possa ocorrer e sua verdadeira magia não lhe seja roubada. Não se pode admitir a existência do autor sem que se admita a existência de heróis, sujeitos que transcendem a facticidade dada pelo enredo e que ajudam a mascarar a ideia por trás do texto. O afã do autor é justamente o de contar as histórias ou estórias dos heróis, por isso eles só existem na medida em que há algo a ser contado a respeito de alguém, de um sujeito. Logo, conclui-se que apresentar ideias claras e teses diretas seria a própria destruição da literatura 
romanesca, já que o romance precisa da obscuridade e de contornos retóricos. Apresentar ideias claras e teses diretas seria denunciar o autor, fazê-lo aparecer ao mesmo tempo como uma ficção, uma imagem infeliz e opaca, esmaecida dentro de um aparato retórico. $\mathrm{O}$ autor, segundo as ideias de Beauvoir tem de ficar escondido, é melhor que seja um anônimo, não num sentido normativo, mas na medida em que não demonstra suas ideias claramente.

Em objeção a si mesma, ou seja, ao fato de os romances não poderem ser cunhados a partir de uma lógica meramente racional, Beauvoir afirma que compor um romance metafísico é mera destreza, de tato, de arte. O autor pode dissimular e enganar o leitor. Permanecer invisível sem demonstrar o que quer e ao que veio; obscurecer as próprias teorias e visões de mundo. A trapaça então resultará em uma obra filosófico-literária, se assim for a vontade do escritor. Esse fato causa irritação aos leitores, que com razão proclamam que o autor age, então, de má fé. Admite-se que parte do ofício da arte é uma mentira, um engano. Uma imagem imperfeita, cópia da cópia, em uma alusão a Platão.

Com efeito, essa seria uma experiência rasa que reduz a literatura ao entretenimento, ao divertimento gratuito e fugaz. A literatura almeja mais. Almeja superar o plano imaginário e os limites da experiência vivida. A tarefa então exige um afã transcendente do autor. Ele próprio terá que participar da investigação que resulta no romance e que convida o leitor. Situando-se nessa experiência-limite, arrancará dela um sentido e tentará atrair o leitor para a adesão. Tudo ainda deve permanecer no plano do quase dito, do não claro. Um plano limite e frágil que impõe a destreza de um arqueiro para ser executado.

As personagens então não serão compostas a partir de ideias fabricadas a priori, pelo contrário: elas se revelarão quase que espontaneamente no desenrolar da obra. $\mathrm{O}$ autor experimenta a liberdade a partir dos mistérios e dos desígnios que suas personagens vivenciam. É a partir da propriedade de se conseguir narrar uma história sobre os outros, ainda que ficcional, que o autor se realiza como sujeito livre. Sua liberdade depende então da obra que cunha. Não a fabrica como uma ferramenta, de acordo com Beauvoir; o verbo seria até pejorativo, segundo a autora, ao se tratar da obra literária.

Análoga a uma verdade científica, a obra literária deve ser confrontada com o próprio fato de o autor acreditar naquilo que escreve. Se assim quer ou pretende que o leitor acredite e atravesse a narrativa contada, o autor deverá confrontar os desígnios, os mistérios que conta, daí o autor descobrirá um sentido e em nome deste significado irá cunhar problemas, saltos e soluções imprevisíveis. A obra por fim ganhará independência do autor. Será carne e osso e uma autêntica aventura espiritual (BEAUVOIR, 1965, p. 85). 
A ideia possuiria uma peculiaridade: é furtiva e independente. Escapa aos exemplos dados em um tratado filosófico. Quando apresentada no meio de uma obra literária, impõe-se a sua dependência do mundo e seus desdobramentos se tornam inesperados. Um conceito ou uma ideia deixa de ter uma aplicação prática e definida. Ganha liberdade em uma expressão totalmente nova e imprevisível. É este o elemento crucial que Beauvoir utiliza para defender a categoria que chama de romance metafísico. Retoma-se aqui a afirmação de que não se faz metafísica como se faz matemática ou física; mas sim se é metafísico. “[...] é realizar em si a atitude metafísica que consiste em pôr-se na sua totalidade em face da totalidade do mundo." (BEAUVOIR, 1965, p. 87).

Toda atitude humana possui consigo um significado metafísico. É justamente na ação que esse sentido oculto nos aparece passível de apreensão. A atitude humana é então metafísica e ela pode ser explicada, elaborada ou ainda explicitada em dois modelos primordialmente distintos, a saber, o do tratado filosófico e o da obra literária. Cada um dos dois modelos possui especificidades, de modo que, se concebermos filosofia e literatura em uma distinção que preze por uma ideia de pureza, ou seja, de uma pura filosofia e de uma pura literatura, não será possível intercalá-las e criar um duplo.

É com base nessa ideia que Beauvoir afirma que seria impossível criar um romance aristotélico, spinozista ou leibniziano. Mas por quê? O tratado filosófico impõe um sistema universal atemporal. Seus conceitos são cunhados e apresentados de modo a possuírem essa característica alheia ao mundo, ao menos é assim que a autora concebe as metafísicas citadas: como universais, atemporais e distintas do mundo. Já a obra literária é sempre mundana. Ela está inserida em um contexto de ideias, objetos, pessoas que a firmam enquanto parte deste mundo que ela mesma forja e revela. Em suma: há um aspecto subjetivo que a literatura mantém, enquanto a filosofia, a priori, deveria ser imparcial.

Contudo, Beauvoir afirma que há filosofias que mantêm o aspecto subjetivo em jogo. O existencialismo seria uma delas. Ainda de acordo com Simone de Beauvoir, Platão, sem saber o que fazer com os poetas, consciente da capacidade persuasiva de seu ofício, resolve bani-los da polis. $\mathrm{O}$ ato se inscreve no fato de que Platão não percebe que ele mesmo é um deles, na medida em que seu método dialético é por si só literatura transfigurada em filosofia; ou ainda, conceitos filosóficos expostos de forma poética. $O$ banquete parece ser o ápice da habilidade poética de Platão, ao apresentar as teses sobre o amor em imagens e apresentar relações íntimas de maneira sutil. A confusão ciumenta formada por Agatão, Sócrates e Alcibíades em um triângulo amoroso, em que o ciúme é presente, nos leva a refletir 
propriamente sobre a natureza de Eros, ou melhor, as naturezas expostas ao longo do diálogo. Se as teses sobre o amor ficassem no plano da apresentação direta, cujo tom da linguagem seria de clareza, o diálogo perderia, no mínimo, metade do seu significado. É só na medida em que no Banquete se trata também de uma obra literária que ele é capaz de tocar e carregar o leitor ao sentido máximo que o amor possui, conforme apresentado na obra. Não por meio de um simples tratado, mas de uma literatura narrativa. Haveria outra possibilidade de falar sobre o amor senão com poiésis?

Nem mesmo Hegel escapa, ao cunhar sua Fenomenologia do espírito, de admitir uma espessura carnal a se cumprir. É preciso sair da filosofia e da metafísica pura para confrontar suas ideias. É necessário, segundo Beauvoir (1965, p. 90), para contar adequadamente sua aventura, recorrer aos mitos literários de Don Juan e de Fausto.

[...] é necessário, para contar adequadamente a sua aventura, conferir-lhe uma certa espessura carnal; na Fenomenologia do Espírito Hegel recorre a mitos literários tais como Don Juan e Fausto, pois drama da consciência infeliz só encontra a sua verdade num mundo concreto e histórico. Quanto mais vivamente um filósofo sublinha o papel e o valor da subjetividade, mais será levado a descrever a experiência metafísica sob a sua forma singular e temporal. (BEAUVOIR, 1965, p. 90).

Quanto mais um filósofo ou a filosofia apreenderem a subjetividade e seu valor, mais será possível descrever e revelar a experiência metafísica singular inerente à ação humana. Kierkegaard recria a história de Abraão e Isaac em Terror e tremor de maneira romanesca, distinto do escrito original em hebraico, cujo texto foi propositalmente forjado, seja por obra de um homem ou do próprio Deus, de forma obscura, pouco dita (AUERBACH, 2001, p. 17). A graça do texto sagrado em questão está mais naquilo que não foi escrito quando nas tábuas da lei se esculpiu a narrativa. Os vazios existentes na forja das letras hebraicas dizem mais a respeito da proposta infinitamente hermenêutica que o próprio texto escrito. É nessa hiância que o texto sagrado emerge com puros significados. Por conseguinte, Kierkegaard, como todo bom escritor aos olhos beauvoirianos, conduz o seu leitor a um caminho traçado. Para atingir seu objetivo foi necessário adotar a forma de romanesca prosaica, para não deixar espaço para interpretações. Afinal, ainda que romanesco, tratava-se de uma obra de cunho meramente filosófico. O drama de Abraão só pôde ganhar significado humano em uma interpretação do texto sagrado feita com destreza por Kierkegaard. É novamente em um mundo humano e 
concreto que o drama pode ser concebido. Não se pode, pois, falar dos assuntos humanos fora do mundo humano.

Mas não seria a transcendência um assunto alheio ao mundo, sendo assim, portanto, inominável e inefável? Falar sobre sua inacessibilidade é já falar sobre ela mesma. A transcendência mais do que forjada na linguagem ocorre em atitude metafísica com o próprio corpo. É essa talvez a distinção fundamental entre Sartre e Beauvoir, aliás, entre Beauvoir e os demais existencialistas. Para a filósofa o transcendente é aqui no mundo e não mero estado de consciência expresso no alhures do espírito. É, pois, consciência no mundo, no corpo; não em disjunção ou adição, mas em unidade.

A filosofia existencialista tem sido apresentada em tratados ou ficções para conciliar o objetivo e o subjetivo, o absoluto e o relativo bem como o atemporal e o a-histórico. Pretende assim encontrar a essência no clamor da existência, e ao encontrá-la será na literatura evocada de maneira singular. $\mathrm{O}$ escritor aqui se encontra não diante de verdades filosóficas préestabelecidas para em seguida manifestá-las com o uso de alguma retórica, mas sim revela o caráter singular da existência, o drama e por fim a ambiguidade. Diz Beauvoir que nenhuma descrição intelectual poderia apresentar esta experiência em sua integridade de maneira adequada (1965, p. 91). É necessário então mostrá-la em sua totalidade, na relação viva que é ação e sentimento, antes de se tornar pensamento.

O romance metafísico que Beauvoir tanto valoriza se realiza quando a pura filosofia e a pura literatura fracassam. Ele evoca em sua unidade viva a fundamental ambiguidade de um destino nosso e que se inscreve uma vez só no tempo e na eternidade.

Simone de Beauvoir termina seu curto ensaio falando sobre Kafka. Diz-nos que, sobre a imanência, Kafka melhor a trata em forma de romance. Em seguida, parafraseando Blanchot, a autora concorda que, ao ler Kafka, ou se entende demasiado ou demasiado pouco (1965, p, 94). A nota pode ser aplicada a todos os romances metafísicos em geral, desde que o leitor não se esqueça de que ele mesmo colabora para o êxito da categoria, "pois o próprio do romance é precisamente apelar para sua liberdade".

Agora é preciso demonstrar, ainda que de forma sucinta, como Beauvoir articula suas ideias em A convidada. Trata-se de expor teses filosóficas no meio do romance, dentro do enredo, sem assim parecer claramente ao leitor. É claro que um leitor filósofo talvez consiga perceber tais sutilezas, e é isto que será feito, mas a ideia é diluir a filosofia em meio à dramaturgia do romance.

Gebert e Françoise conversam: 
(..)

- Sim, é aborrecido - disse, retomando a conversa.

- Quando conhecemos a pessoa - comentou Gerbert - as coisas são diferentes.

- É... Nunca podemos pensar que os outros são consciências que têm um sentimento de si próprias, como nós temos - disse Françoise. - Quando descobrimos isso é terrível. Temos a impressão de que passamos a ser apenas uma imagem refletida no cérebro de alguém. Mas isso quase nunca acontece, ou, em todo caso, nunca acontece completamente.

(...)

- Ora... Os pensamentos dos outros causam-me a mesma impressão que as suas palavras, ou os seus rostos: admira-se de que eu não seja ambiciosa; mas a razão é essa, justamente. Não preciso conquistar um lugar privilegiado no mundo, pois parece-me que já estou instalada nele. (BEAUVOIR, 1976, p. 17).

O que Françoise descobre é a angustia, é o fato de que um ser em si não consegue lidar bem com um outro ser em si que aparece para ele como para si. Não se realiza a síntese, e a consciência entra em uma espécie de colapso no qual o Eu absoluto quer a tudo dominar. $\mathrm{O}$ que a personagem descreve é o imperialismo da consciência, já colocado como epígrafe do romance. É atribuída a Hegel a seguinte frase: "Toda consciência tem por objetivo a morte de outra”. Seu desdobramento é a impossibilidade de se conceber como outro para o outro. Isto gera angústia, pois não se pode ter controle daquilo que lhe é alheio, então se tenta aniquilálo. A tentativa é falha e a relação se dá sempre nessa alienação no outro como objeto. Ser uma imagem no cérebro de alguém é ser um fantasma, é o contraste do que aparece a seguir: um ser instalado no mundo, que não precisa conquistar qualquer espaço privilegiado. Beauvoir, de forma romanesca, expõe a não realização da dialética do em si com o para si e também o fato de compor o mundo e não meramente habitá-lo em uma dualidade sujeito x objeto. É esta, pois, a concretude da experiência da alteridade que tanto a autora quer atingir, sendo a sua principal questão filosófica e literária.

\footnotetext{
Xavière olhava atentamente a dançarina, sem ter consciência do efeito que esse interesse apaixonado provocava no seu rosto e na sua mão, que percorria os contornos da xícara. Só Françoise, porém, era sensível aos seus movimentos. Os gestos de Xavière, a sua figura, a sua vida, mesmo, necessitavam de Françoise para existir. Nesse instante, Xavière nada mais era para ela própria que um gosto de café, uma música lancinante, uma dança, uma sensação de leve bem-estar; mas para Françoise a juventude de Xavière, os seus dias estagnados, a repugnância que sentia por esse tipo de vida compunham uma história romanesca, tão real como o contorno delicado das suas faces. (BEAUVOIR, 1796, p. 23).
}

O drama de Xavière ao perceber que sua existência necessita de Françoise é o drama universal que toda consciência tem de passar para formar-se consciência. Quando disso se apercebe, de que só se é singular na medida em que há pluralidade, confunde-se com o resto, 
com as coisas do mundo; quer-ser qualquer coisa menos essa imagem projetada na consciência de outro. Trata-se de expor um esquema hegeliano através de imagens, sensações. É o drama da fenomenologia de Hegel (FE, §178) transformado em romance. É a essa espessura carnal da tese filosófica que a autora se refere em Literatura e metafísica. Só quando uma filosofia ganha corpo, e isso é impossível quando a filosofia tenta ser pura filosofia, ou seja, puro pensamento, pura abstração, é que ela passa a fazer sentido no mundo. Por isso, seus romances metafísicos são justificados. Eles conseguem unir ambas as coisas, que nos foram tradicionalmente apresentadas em um dualismo falso: corpo e consciência. Aqui há o ser que é corpo e consciência, e não só espírito universal ou um corpo passivo, acidental.

[...] Olhou Xavière, que dançava, com a cabeça para trás e o rosto extático. Para ela, que ainda nao vivera, tudo era possível e esta noite encantada continha promessas de mil seduções desconhecidas. Para esta jovem, como para aquela mulher, de coração pesado, o momento presente tinha um sabor azedo mas inesquecível. E eu? Pensou. Espectadora. Mas este jazz, este gosto de uísque, esta luz alaranjada, tudo isso não era apenas um espetáculo. Era preciso transformar tudo em qualquer outra coisa. Em quê? Dentro da alma rude e tensa de Élisabeth a música transformava-se suavemente em esperança. Xavière, por sua vez, convertia-a numa espera apaixonada. Só Françoise, nada encontra, em si própria, que afinasse um desejo, ou a saudade de qualquer coisa que lamentasse ter perdido. (BEAUVOIR, 1976, p. 35).

O movimento de dar sentido à própria existência, é isto que está descrito nas linhas de Beauvoir. Três mulheres, de diferentes idades e personalidades, em uma mesma situação, tendo percepções absolutamente distintas, que culminam em sentidos distintos. Duas delas transformam o sentido em desejo por algo externo; um objeto. Uma, Françoise, consegue perceber o niilismo de tudo à sua volta, a ausência de sentido prévio que as coisas têm. $\mathrm{O}$ nada. Vê-se confrontada com a obrigação de dar sentido ela mesma ao mundo.

Inicialmente, descreveu-se a ambiguidade e partimos do princípio em comum com a filosofia niilista, de que nada possui sentido prévio; o sentido advém do movimento em sua busca, ou seja, de uma ação. Beauvoir apresenta a mesma tese dentro de seu romance, fazendo que as personagens vivenciem esse estágio da existência, aquele em que se apercebe a ausência de sentido das coisas e do próprio mundo, e se apercebe também que se é dono das rédeas do movimento de significar. É um esboço simplificado das premissas da filosofia existencialista.

Vê-se que a literatura ocupa papel central dentro da obra beauvoiriana. Para entender sua filosofia é necessário ler sua literatura, pois não há a clara separação entre as duas coisas. 
Em sua obra, filosofia é literatura e literatura é filosofia. A única distinção se dá no modo pelo qual as ideias e teses são expostas. Podem ser mascaradas num enredo, como em seus romances, ou explicados à exaustão, como em seus ensaios. De todo modo, a filósofa, à revelia da própria vontade e por treino (tasking), tem um pensamento original que a situa independente de Sartre, ainda que haja uma tentativa frustrada de amalgamar os dois.

\section{REFERÊNCIAS}

AGUIAR, Odilio Alves. Pensamento e narração em Hannah Arendt. In: Hannah Arendt. Diálogos, reflexões, memórias. Organização de Eduardo Jardim de Moraes e Newtom Bignotto. Belo Horizonte: UFMG, 2003.

ARENDT, Hannah. A condição humana. Tradução de Adriano Correia. Rio de Janeiro: Forense Universitária, 1989.

ARENDT, Hannah. Compreender. Formação, exílio e totalitarismo. Tradução de Denise Bottman. São Paulo: Companhia das Letras, 2008b.

ARENDT, Hannah. Crises of the Republic. Nova Iorque: Harcourt, 1972.

ARENDT, Hannah. Entre o passado e o futuro. Tradução de Mauro W. Barbosa. São Paulo: Perspectiva, 2013.

ARENDT, Hannah. The Hannah Arendt Papers at the Library of Congress. Disponivel em: <http://memory.loc.gov/ammem/arendthtml/arendthome.html>. Acesso em 26 maio 2015.

ARENDT, Hannah. Homens em tempos sombrios. Tradução de Denise Bottman. São Paulo: Companhia de Bolso, 2008a.

ARENDT, Hannah. As origens do totalitarismo. Tradução de Roberto Raposo. São Paulo: Companhia das Letras, 2010b.

ARENDT, Hannah. O que é política? Tradução de Reinaldo Guarany. Rio de Janeiro: Bertrand, 2004a.

ARENDT, Hannah. Responsabilidade e julgamento. Tradução de Rosaura Eichenberg. São Paulo: Companhia das Letras, 2004b.

ARENDT, Hannah. Sobre a revolução. Tradução de Denise Bottman. São Paulo: Companhia das Letras, 2014.

ARENDT, Hannah. A vida do espírito. Tradução de Cesar Auguto de Almeida, Antonio Abranches e Helena Martins. Rio de Janeiro: Civilização Brasileira, 2010a.

ARENDT, Hannah. Vita activa oder vom tätigen Leben. Munique e Zurique: Piper Taschenbuch, 2007.

Sapere aude - Belo Horizonte, v. 8, n. 16, p. 508-521, ago./dez. 2017 - ISSN: 2177-6342 
AUERBACH, Erich. Mímesis - A representação da realidade na literatura ocidental. Tradução da Equipe Perspectiva. São Paulo: Perspectiva, 2001.

BEAUVOIR, Simone de. A convidada. Tradução de Vítor Ramos. São Paulo:Círculo do Livro, 1976.

BEAUVOIR, Simone de. A força das coisas. Tradução de Maria Helena Franco Martins. Rio de Janeiro: Nova Fronteira, 2009.

BEAUVOIR, Simone de. Na força da Idade. vol. I. Tradução de Sergio Milliet. São Paulo: Difusão Europeia do Livro, 1961.

BEAUVOIR, Simone de. Literatura e metafísica. In: O existencialismo e a sabedoria das nações. Tradução de Manuel de Lima e Bruno da Ponte. Porto: Minotauro, 1965.

BEAUVOIR, Simone de. Por uma moral da ambiguidade. Tradução de Sergio Milliet. Rio de Janeiro: Editora Nova Fronteira, 2005.

BEAUVOIR, Simone de. O segundo sexo. v. I. Tradução de Sergio Milliet. São Paulo: Difusão Europeia do Livro, 1970a.

BEAUVOIR, Simone de. O segundo sexo. v. II. Tradução de Sergio Milliet. São Paulo: Difusão Europeia do Livro, 1970 b.

BEAUVOIR, Simone de. The second sex 25 years later. Society, v.13(2) (Janeiro-Fevereiro), 1976.

BRUEHL, Elizabeth Young. Por amor ao mundo - A vida e obra de Hannah Arendt. Tradução de Antônio Trânsito. Rio de Janeiro: Relume Dumará, 1997.

CALADO, Eliana. Literatura como projeto existencial: a trajetória da escritora Simone de Beauvoir em sua narrativa autobiográfica. Revista Graphos, João Pessoa, v. 13 - n. 2. 2011.

HEGEL, G. W. F. Fenomenologia do espírito - Parte 1. Tradução de Paulo Meneses e KarlHeinz Efken. Petrópolis, RJ: Vozes, 1992.

KATZ, Juliana Albuquerque. Simone de Beauvoir's case for philosophical autonomy and the Possibilities within the methaphysical novel. Sapere Aude - Belo Horizonte, v.3 - n.6, p.136147 - 2o sem. 2012.

KRISTEVA, Julia. Hannah Arendt: Life Is a Narrative. Toronto: Universidade de Toronto, 2001.

LÄFER, Celso. Experiência, ação e narrativa: reflexões sobre um curso de Hannah Arendt. Estudos Avançados, v. 21, n. 60, São Paulo: Maio, 2007.

PONTY, Maurice Merleau. Fenomenologia da percepção. Tradução de Carlos Alberto Ribeiro de Moura. São Paulo: Martins Fontes, 1999. 
POUND, Ezra. ABC of reading. Boston e Londres: faber and faber, 1991.

SARTRE, Jean-Paul. O ser e o nada. Tradução e notas de Paulo Perdigão. Petrópolis, RJ:

Vozes:, 2011.

SIMMONS, Margaret. Simone de Beauvoir: an interview. Feminist Studies, v. 5, n. 2 (Verão, 1979).

SIMMONS, Margaret. Two Interviews with Simone de Beauvoir. Hypatia v. 3, n. 3 (Inverno, 1989).

SHAKESPEARE, William. A tempestade. Edição bilíngue. Tradução de Rafael Raffaelli. Florianópolis: UFSC, 2014.

SJÖHOLM, Cecilia. Doing aesthetics with Arendt - How to see things. Nova Iorque: Columbia University, 2015. 